\title{
Evaluation of Success Rate of Early Loading Versus Delayed Loading Single-Tooth Implants - Results after 2 Years of Clinical Function
}

\author{
Yukti Panwar', Varun Choudhary ${ }^{2}$ \\ ${ }^{1}$ Department of Dentistry, Saraswathi Institute of Medical Sciences, Hapur, Uttar Pradesh, India, ${ }^{2}$ Department of Periodontology, Army \\ Dental Corps, Pune, Maharashtra, India
}

Email for correspondence: drvarunchoudhary@gmail.com

\begin{abstract}
Background: Success in implant therapy for replacement of one or more missing teeth has been well documented. The original surgical protocol considered a healing period of 3-6 months free from functional loading as optimal to achieve a successful osseointegration. The current scientific literature supports the concept that implants can be loaded early or immediately. Aims and Objectives: The aim of the present retrospective study was to compare early loading (within 1-2 weeks) with delayed loading (4-5 months) single-tooth implant, results after 2 years in terms of success rate by assessing peri-implant changes using clinical parameters, radiographic marginal bone level, and implant stability. Materials and Methods: A total of 20 patients (mean age $=31.15$ years) treated by the implants for the rehabilitation of a single missing tooth in either jaw were examined. The test group was treated by early loading implants while the control group by delayed loading implants. Clinical and radiographic measurements were recorded around each implant. Results: At 2 years, the survival rate of implants in the control group (delayed loading implants) was $100 \%$ at 5 -year follow-up while in the test group (early loading implants), it was $90 \%$. Conclusion: It can be concluded that single-tooth implant may be loaded with predictable outcome as early as 2 weeks after installation.
\end{abstract}

Key words: Delayed loading, dental implants, early loading

\section{INTRODUCTION}

Success in implant therapy for replacement of one or more missing teeth has been well documented for more than three decades. ${ }^{[1]}$ They have been successful largely due to the development of design and implantation procedures that result in direct bone-implant interface without detectable intervening fibrous tissue. ${ }^{[2]}$ The original surgical protocol proposed by Adell et al. and Brånemark et al. considered a healing period of 3-6 months

\begin{tabular}{|l|l|}
\hline Quick Response Code & Article Info: \\
\hline doi: 10.5866/2019.11.10061 & $\begin{array}{l}\text { Received: 03-04-2019 } \\
\text { Revised: 07-05-2019 } \\
\text { Accepted: 11-06-2019 } \\
\text { Available Online: 01-07-2019, (www. } \\
\text { nacd.in) () NAD, 2019 - All rights reserved }\end{array}$ \\
\hline
\end{tabular}

free from functional loading as optimal to achieve a successful osteointegration. ${ }^{[3,4]}$ The other reasons for using this approach were to prevent apical down growth of mucosal epithelium and to minimize the risk of infection due to early loading during the initial healing period. Only on completion of this healing period, mucosa piercing abutments are placed and the supra connections connected. ${ }^{[5]} \mathrm{A}$ reanalysis of this original experimental design has questioned the necessity for a long implant healing period. ${ }^{[6]}$ Implant that is loaded after healing period (delayed loading) has high biologic stability, but it also has the disadvantage of prolonged treatment time. ${ }^{[7]}$ The current scientific literature supports the concept that implants can be loaded early or immediately. A study conducted by Muthukumar et al. showed that immediate loading has higher failure rate compared to early loading. ${ }^{[8]}$ 
With advances in biomaterial technology and continuous clinical research have provided clinicians with improved protocols to provide more advanced treatment options to satisfy continuously increasing patient's expectation of reduced treatment time, improved esthetics, and increased comfort. Roccuzzo et al. assessed periimplant conditions of early loading implants in a prospective split-mouth controlled study and suggested that implant may very well suitable for early loading at 6 weeks. ${ }^{[9]}$ Cochran et al. in a prospective multicenter cohort study involving 133 patients with 383 implants found that implants could be successfully restored after 6 weeks of loading and yielded a success rate $>99 \%, 2$ years after prosthetic restoration. ${ }^{[10]}$

Considerable outcome variations on immediate or early implant loading for single-tooth replacement, Ericsson et al., 2000, have shown the results and crestal bone changes to be equivalent to those with an established conventional protocol. ${ }^{[11]}$ The early loading of implant supporting a full-arch prosthesis in the edentulous mouth has also been studied. ${ }^{[12]}$ However, only few studies regarding early loading of implants supported single-tooth crowns with long-term follow-up are available in literature. Therefore, the aim of the present retrospective study was to compare early loading (within 1-2 weeks) with delayed loading (4-5 months) single-tooth implant, results after 2 years in terms of success rate by assessing peri-implant changes using clinical parameters, radiographic marginal bone level, and implant stability.

\section{MATERIALS AND METHODS}

\section{Study Population}

A total of 20 systemically healthy patients (mean age $=31.15 \pm 7.28$ years) who were treated by the implants for the rehabilitation of a single missing tooth in either jaw in the SGT Dental College Hospital and Research Institute, Gurgaon, were examined for the present study. The test group was treated by early loading implants while the control group by delayed loading implants. Before initiating this study, the purpose and design of this clinical trial were explained to the patients and informed consent was signed by every patient. The study protocol was first approved by the ethical committee of SGT Dental College Hospital and Research Institute, Gurgaon.

\section{Clinical Measurements}

Patient oral hygiene status was evaluated by the plaque index (PI) as an expression of the level of full-mouth supragingival plaque accumulation. Gingival inflammation was assessed by papillary bleeding index (PBI).

\section{Measurements around Implant \\ Clinical measurement}

Clinical measurements recorded around each implants were modified PI, modified gingival index, probing measurements, and Clinical Implant Mobility Scale (CIMS). Furthermore, the width of the keratinized peri-implant mucosa was assessed on midbuccal aspect of each implant.

\section{Radiographic measurement}

Bone level was measured using standardized intraoral periapical radiograph. Radiograph was obtained at baseline and 2 years recall visit. To assess the changes at the interproximal alveolar crestal bone height, the distance from the implant shoulder to the most coronal bone-to-implant contact (DIB) was determined both at the mesial and distal aspect of each implant and was expressed in $\mathrm{mm}$ [Figure 1].

\section{Statistical Analysis}

The means and standard deviation (Mean $\pm \mathrm{SD}$ ) values were calculated for all clinical parameters including probing pocket depth (PPD), clinical attachment level (CAL), gingival recession, PI, PBI, and radiographic marginal bone loss. The mean data were analyzed for the statistical significance by standard statistical method.

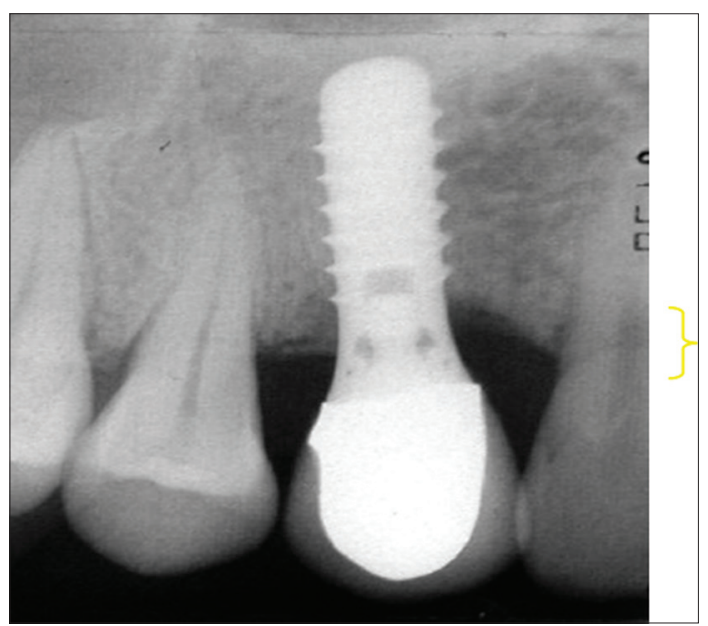

Figure 1: IOPA radiograph showing bone level at the interproximal alveolar crestal bone 


\section{RESULTS}

Twenty systemically healthy patients, 12 males and 8 females, with a mean age of $31.15 \pm 7.28$ years who were treated for single missing tooth either in maxilla/mandible with early loading (test group) or delayed loading (control group) single-tooth implant were included in the present study. The test group had four maxillary central incisor missing and six mandibular molar missing, which were replaced by $10 \mathrm{Hi}$-Tech implants (V-TPS) by early loading protocols, while the control group had 10 mandibular molar missing, which were replaced by 10 Pitt-Easy implants (SLA) by delayed loading protocols [Table 1]. The sizes of implants in the test group were of $2.8 \mathrm{~mm} \times 10 \mathrm{~mm}$ in three patients, $2.8 \mathrm{~mm} \times 13 \mathrm{~mm}$ in one patient, and $3.7 \mathrm{~mm} \times$ $10 \mathrm{~mm}$ in one patient, $3.7 \mathrm{~mm} \times 13 \mathrm{~mm}$ in five patients, while sizes of implant in the control group were of $3.25 \mathrm{~mm} \times 10 \mathrm{~mm}$ in four patients, $3.25 \mathrm{~mm} \times 12 \mathrm{~mm}$ in one patient, $3.7 \mathrm{~mm} \times 10 \mathrm{~mm}$ in two patients, and $3.7 \mathrm{~mm} \times 13 \mathrm{~mm}$ in five patients [Table 2].

During the course of the study, no implants had to be removed. None of the selected patients had dropped out before the termination of the study. At 2 years, the mean PI score was increased in both the test $(0.92 \pm 0.37)$ and control groups $(0.95$ \pm 0.22 ) and also the mean PBI scores were increased in both the test $(0.85 \pm 0.35)$ and control groups $(1.15 \pm 0.25)$ compared to baseline score, but the difference was statistically non-significant for both groups [Table 3; Graph 1]. Difference in the mean PPD reduction, CAL gain, and mean CIMS score for the test group and control group was found to be non-significant, whereas difference in the width of keratinized gingiva between both groups was significant [Table 4; Graph 2]. The control group showed greater amount of marginal bone loss $(2.2 \pm 1.11)$ as compared to $1.5 \pm 0.39$ in the test group although difference was non-significant [Table 5; Graph 3].

\section{DISCUSSION}

The purpose of the present retrospective study was to evaluate the success rate of early loading (7-14 days) with delayed loading (4-5 months) after 2 years of clinical function. The results showed that functional loading of early implants as early as $7-14$ days as well as delayed loading at 4-5 months did not result in statistically significant different outcomes.

Table 1: Distribution of single-tooth edentulous sites treated
with implants

Table 2: Dimensions of implants

\begin{tabular}{lcc}
$\begin{array}{l}\text { Dimensions } \\
\text { \{diameter and length\} }(\mathbf{m m})\end{array}$ & \multicolumn{2}{c}{ Number of implants } \\
\cline { 2 - 3 } & $\begin{array}{c}\text { Test } \\
\text { group }\end{array}$ & $\begin{array}{c}\text { Control } \\
\text { group }\end{array}$ \\
\hline $2.8 \times 10$ & 3 & - \\
$2.8 \times 13$ & 1 & - \\
$3.25 \times 10$ & - & 4 \\
$3.25 \times 12$ & - & 1 \\
$3.7 \times 10$ & 1 & 2 \\
$3.7 \times 13$ & 5 & 3 \\
\hline
\end{tabular}

Table 3: Full-mouth plaque index and full-mouth papillary bleeding index at baseline and 2-year follow-up (MV \pm SD)

\begin{tabular}{lccc} 
Parameters & Group & Baseline & 2 years \\
\hline Plaque index & Test & $0.79 \pm 0.08$ & $0.92 \pm 0.37$ \\
& & & NS \\
& Control & $0.79 \pm 0.03$ & $0.95 \pm 0.22$ \\
& & & NS \\
Papillary & Test & $0.75 \pm 0.14$ & $0.85 \pm 0.35$ \\
bleeding index & & & $\mathrm{NS}$ \\
& Control & $0.77 \pm 0.03$ & $0.89 \pm 0.25$ \\
& & & $\mathrm{NS}$ \\
\hline
\end{tabular}

S: Statistically significant $(P<0.05)$; NS: Statistically non-significant $(P>0.05)$

In the present study, one implant in the test group showed mobility score 2 (CIMS) at 2 months after restoration due to periapical infection. However, after 1 week antibiotic therapy, periapical infection resolved with decreased in implant mobility after 2 weeks and implant becomes stable. The definite prosthesis was placed after 3 weeks. It should be noted, however, that at 2-year examination, same implant presented no clinical or radiographic differences from the other implants. Hence, the observation of occasional complications does not seem to question the overall success of early loading. ${ }^{[8]}$

The influence of oral hygiene on implant success has been controversial. ${ }^{[13]}$ However, it is generally agreed that plaque accumulation could 


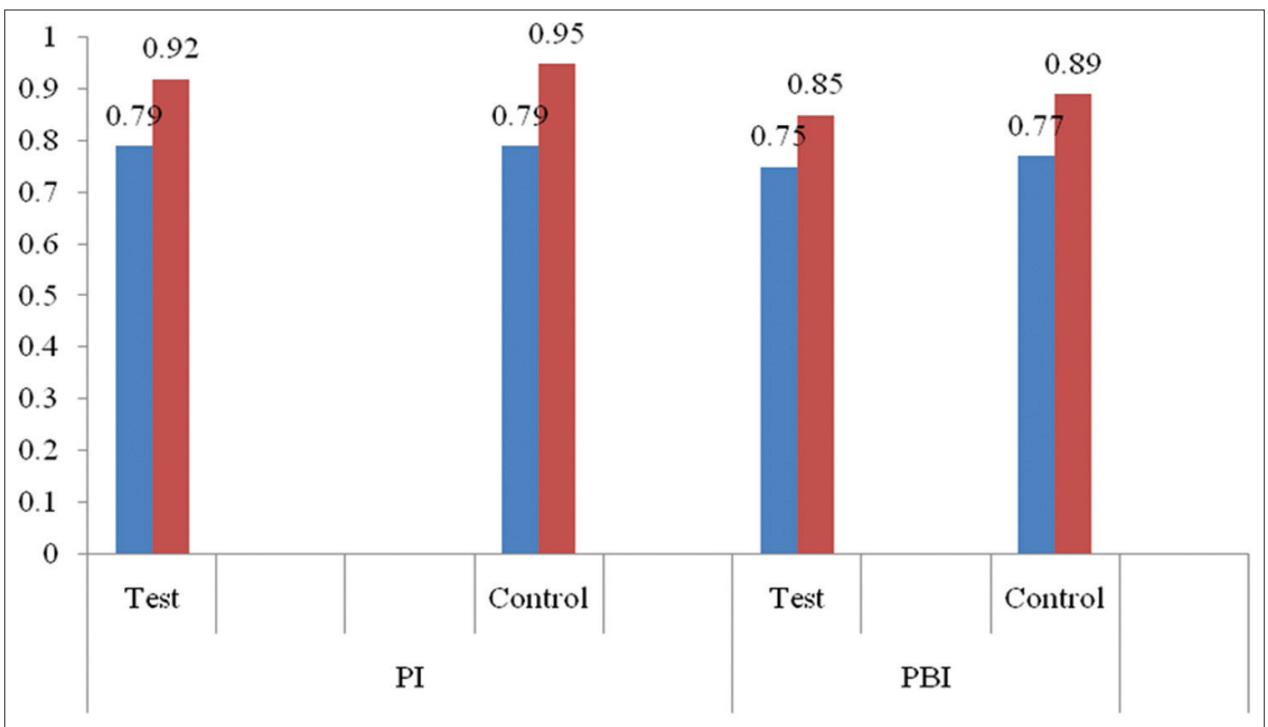

Graph 1: Full-mouth plaque index and full-mouth papillary bleeding index scores at baseline and 2-year follow-up (MV \pm SD)

\begin{tabular}{|c|c|c|}
\hline Parameters & $\begin{array}{l}\text { Test } \\
\text { group }\end{array}$ & $\begin{array}{c}\text { Control } \\
\text { group }\end{array}$ \\
\hline $\begin{array}{l}\text { Postpartum depression } \\
\text { Reduction }\end{array}$ & $2.68 \pm 0.47$ & $\begin{array}{l}2.95 \pm 0.51 \\
\text { NS }\end{array}$ \\
\hline CAL gain & $2.68 \pm 0.47$ & $\begin{array}{c}2.95 \pm 0.51 \\
\text { NS }\end{array}$ \\
\hline $\begin{array}{l}\text { Width of keratinized } \\
\text { gingiva }\end{array}$ & $3.60 \pm 0.52$ & $\begin{array}{c}3.05 \pm 0.6 \\
\mathrm{~S}\end{array}$ \\
\hline $\begin{array}{l}\text { Clinical implant } \\
\text { mobility scale }\end{array}$ & $0.40 \pm 0.51$ & $\begin{array}{c}0.60 \pm 0.84 \\
\text { NS }\end{array}$ \\
\hline Plaque index & $1.35 \pm 0.47$ & $\begin{array}{c}1.08 \pm 0.27 \\
\mathrm{NS}\end{array}$ \\
\hline Papillary bleeding index & $1.2 \pm 0.59$ & $\begin{array}{c}1.01 \pm 0.14 \\
\text { NS }\end{array}$ \\
\hline
\end{tabular}

NS: Statistically non-significant $(P>0.05)$

induce negative mucosal response. In the present study, no significant differences were observed in modified PI score at implant site in both the groups throughout the study period. The majority of scores were 0 , implying that good oral hygiene had been maintained around the implants.

In the present study, the mean marginal bone loss at 2 years in the test group was $1.5 \mathrm{~mm}$, while in the control group, it was $2.2 \mathrm{~mm}$, showing significant marginal bone loss in both groups. However, when the amount of marginal bone

\begin{tabular}{|c|c|c|}
\hline Group & $\begin{array}{c}\text { Amount of } \\
\text { bone present at } \\
\text { baseline }(\mathrm{mm})\end{array}$ & $\begin{array}{c}\text { Amount of } \\
\text { bone loss at } \\
2 \text { years (mm) }\end{array}$ \\
\hline Test & $8.4 \pm 1.74$ & $\begin{array}{c}1.5 \pm 0.39 \\
\mathrm{~S}\end{array}$ \\
\hline Control & $9.6 \pm 0.62$ & $\begin{array}{c}2.2 \pm 1.11 \\
\mathrm{~S}\end{array}$ \\
\hline Difference & $\begin{array}{c}1.2 \pm 0.6 \\
\mathrm{NS}\end{array}$ & $\begin{array}{c}0.5 \pm 0.63 \\
\mathrm{NS}\end{array}$ \\
\hline
\end{tabular}

loss was compared between the test and control group, difference was not statistically significant. Turkyilmaz et al. reported the average marginal bone loss for the test and control group 0.7 and $0.81 \mathrm{~mm}$ at 1 year recall, and 1.06 and $1.16 \mathrm{~mm}$ at 4 years recall, respectively. ${ }^{[14]}$ Vigolo et al. reported $0.8 \mathrm{~mm}$ marginal bone loss for implantsupported single crown 4 years after implant placement. ${ }^{[15]}$ In the present study, marginal bone loss observed in both the groups at 2-year followup was higher than previous reported studies. It could have been resulted from the distribution of the implant sites, as the majority of the implant in the present study were placed (16 of 20) in the posterior region (80\%) where bone quality is relatively poor. 


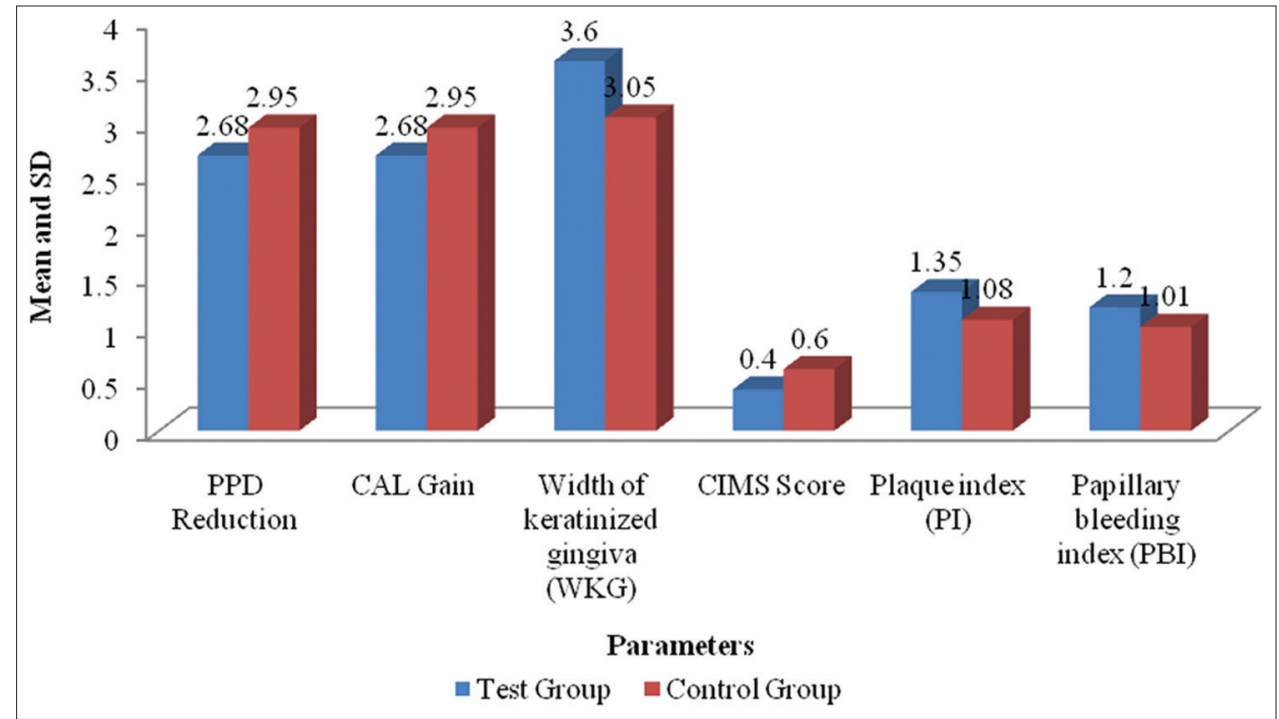

Graph 2: Comparison of clinical parameters at implant sites between the test group (early loading implants) and control group (delayed loading implants) at 2-year follow-up (MV $\pm \mathrm{SD}$; in $\mathrm{mm})$

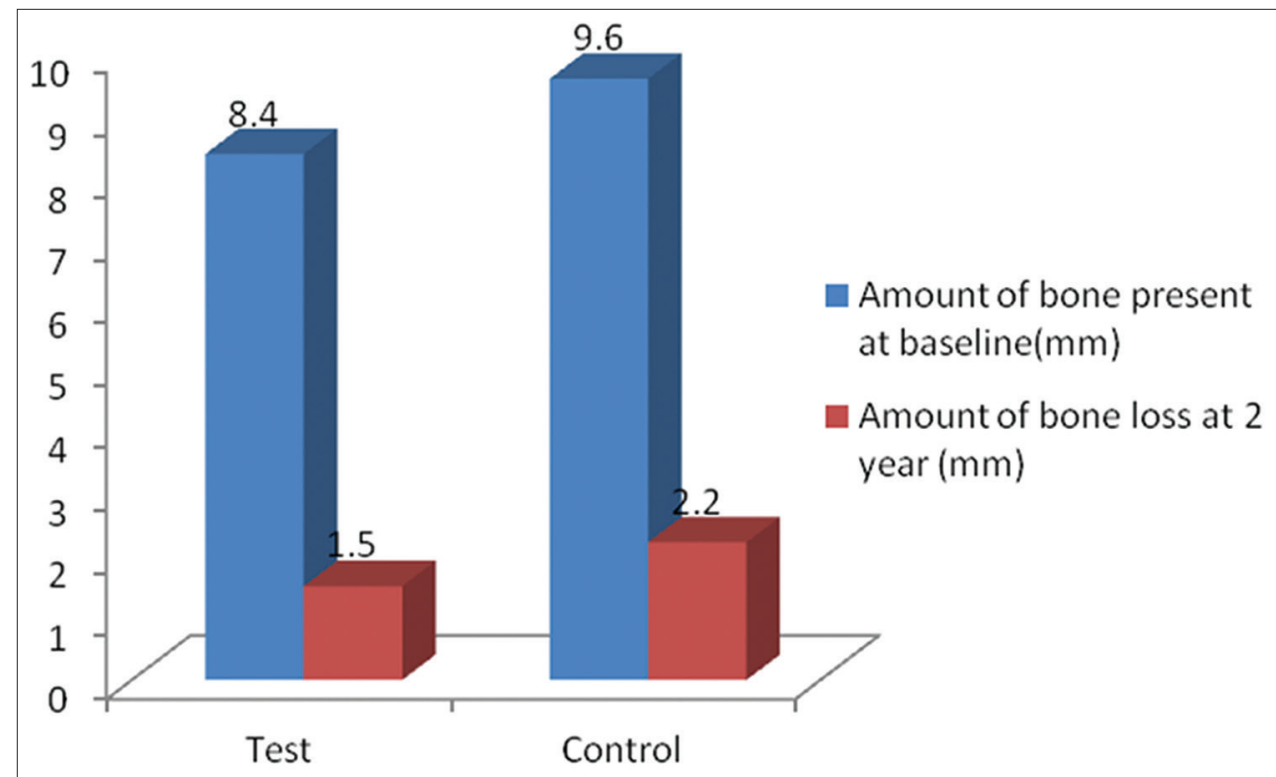

Graph 3: Radiographic bone loss around implants in the test and control group (immediate one stage implants) at 2-year follow-up $(\mathrm{MV} \pm \mathrm{SD} ;$ in $\mathrm{mm})$

In the present study, the survival rate of implants in the control group (delayed loading implants) was $100 \%$ at 2 -year follow-up while in the test group (early loading implants), it was $90 \%$. Findings in the present study are comparable with the previous reported study. Norton (2004) reported $96.4 \%$ survival rate for immediately loaded implants at 20.3 months (range 1330 months) follow-up. ${ }^{[10]}$ After implant placement, while Cooper et al. reported $96.2 \%$ survival rate for single-tooth implants restored 3 weeks after the surgery. ${ }^{[16]}$

At 2 years, the mean CAL in the test group was $2.68 \pm 0.47 \mathrm{~mm}$ while in the control group, it was $2.95 \pm 0.51 \mathrm{~mm}$. However, the difference between the groups was not statistically significant. Weber et al. found that attachments level surrounding the implants were stable over the study period and it was fluctuated over the 5 years period. ${ }^{[17]}$ 
In the present study, the soft tissue was healthy over the entire observation period both in the test and control group. The mean pocket depth at 2 years was $2.68 \pm 0.47 \mathrm{~mm}$ in the test group and $2.95 \pm 0.5 \mathrm{~mm}$ in the control group. Haas et al. reported healthy soft tissues around the implant over the entire observation period despite the subgingival crown margin. ${ }^{[18]}$ Temporary swelling of the peri-implant mucosa was always due to a loosening of the suprastructure and completely disappeared after mechanical stabilization of the crown. The mean pocket depth was $2.2 \mathrm{~mm}$.

Most standard protocols in implant dentistry suggest a healing period of 3 months for mandible and 6 months for maxilla. ${ }^{[19]}$ However, the time required for treatment, the need for additional surgical procedures, and especially the need for indefinite periods of temporization are obstacles that sometimes prevent the patients from implant treatments. To remove these obstacles, it would be beneficial to load implants within the few weeks after implant placement. Studies regarding different types of prostheses have shown that early loading of mandibular implants can provide treatment outcomes comparable to those achieved using standard healing periods before loading. ${ }^{[20]}$ The early loading of implants supporting a fullarch prosthesis in edentulous maxilla has also been studied. ${ }^{[21]}$ However, only few studies regarding early loading of implant-supported single-tooth crowns in the maxilla are available in literature. ${ }^{[22]}$ In the present study, both the test and control implant showed similar clinical and radiographic results after 2 years, suggesting that 15-16 weeks of unloaded healing in the control group did not further improve the treatment outcome.

\section{CONCLUSION}

The result of the present study, therefore, concludes that single-tooth implant may be loaded with predictable outcome as early as 2 weeks after installation. Further, clinical and histological studies are necessary to promote clinical application of this technique.

\section{REFERENCES}

1. Albrektsson T, Zarb G, Worthington P, Eriksson AR. The long-term efficacy of currently used dental implants: A review and proposed criteria of success. Int $\mathrm{J}$ Oral Maxillofac Implants 1986;1:11-25.

2. Hansson HA, Albrektsson T, Brånemark PI. Structural aspects of the interface between tissue and titanium implants. J Prosthet Dent 1983;50:108-13.
3. Adell R, Lekholm U, Rockler B, Brånemark PI. A 15-year study of osseointegrated implants in the treatment of the edentulous jaw. Int J Oral Surg 1981;10:387-416.

4. Brånemark PI, Hansson BO, Adell R, Breine U, Lindström J, Hallén $\mathrm{O}$, et al. Osseointegrated implants in the treatment of the edentulous jaw. Experience from a 10-year period. Scand J Plast Reconstr Surg Suppl 1977;16:1-32.

5. Ericsson I, Nilner K. Early functional loading using Brånemark dental implants. Int $J$ Periodontics Restorative Dent 2002;22:9-19.

6. Szmukler-Moncler S, Piattelli A, Favero GA, Dubruille JH. Considerations preliminary to the application of early and immediate loading protocols in dental implantology. Clin Oral Implants Res 2000;11:12-25.

7. Simunek A, Kopecka D, Brazda T, Strnad I, Capek L, Slezak R, et al. Development of implant stability during early healing of immediately loaded implants. Int J Oral Maxillofac Implants 2012;27:619-27.

8. Muthukumar B, Gopichander N, Katare U. Clinical and radiographic evaluation of single unit implant-retained prosthesis with immediate and delayed loading. SRM J Dent Sci 2010;1:48-50.

9. Roccuzzo M, Bunino M, Prioglio F, Bianchi SD. Early loading of sandblasted and acid-etched (SLA) implants: A prospective split-mouth comparative study. Clin Oral Implants Res 2001;12:572-8.

10. Norton MR. A short term clinical evaluation of immediately restored maxillary TiOblast single tooth implants. Int J Oral Maxillofac Implants 2004;19:274-81.

11. Ericsson I, Nilson H, Lindh T, Nilner K, Randow K. Immediate functional loading of Brånemark single tooth implants. An 18 months' clinical pilot follow-up study. Clin Oral Implants Res 2000;11:26-33.

12. Norton MR. A short-term clinical evaluation of immediately restored maxillary TiOblast single-tooth implants. Int J Oral Maxillofac Implants 2004;19:274-81.

13. Hui E, Chow J, Li D, Liu J, Wat P, Law H, et al. Immediate provisional for single-tooth implant replacement with Brånemark system: Preliminary report. Clin Implant Dent Relat Res 2001;3:79-86.

14. Turkyilmaz I, Avci M, Kuran S, Ozbek EN. A4-year prospective clinical and radiological study of maxillary dental implants supporting single-tooth crowns using early and delayed loading protocols. Clin Implant Dent Relat Res 2007;9:222-7.

15. Vigolo P, Givani A, Majzoub Z, Cordioli G. Cemented versus screw-retained implant-supported single-tooth crowns: A 4-year prospective clinical study. Int J Oral Maxillofac Implants 2004;19:260-5.

16. Cooper L, Felton DA, Kugelberg CF, Ellner S, Chaffee N, Molina AL, et al. A multicenter 12-month evaluation of single-tooth implants restored 3 weeks after 1-stage surgery. Int J Oral Maxillofac Implants 2001;16:182-92.

17. Weber HP, Crohin CC, Fiorellini JP. A 5-year prospective clinical and radiographic study of non-submerged dental implants. Clin Oral Implants Res 2000;11:144-53. 
18. Haas R, Mensdorff-Pouilly N, Mailath G, Watzek G. Brånemark single tooth implants: A preliminary report of 76 implants. J Prosthet Dent 1995;73:274-9.

19. Fischer K, Stenberg T. Early loading of ITI implants supporting a maxillary full-arch prosthesis: 1-year data of a prospective, randomized study. Int J Oral Maxillofac Implants 2004;19:374-81.

20. Payne AG, Tawse-Smith A, Duncan WD, Kumara R. Conventional and early loading of unsplinted ITI implants supporting mandibular overdentures. Clin Oral Implants Res 2002;13:603-9.

21. Ostman PO, Hellman M, Sennerby L. Direct implant loading in the edentulous maxilla using a bone densityadapted surgical protocol and primary implant stability criteria for inclusion. Clin Implant Dent Relat Res 2005;7 Suppl 1:S60-9.

22. Tsirlis AT. Clinical evaluation of immediate loaded upper anterior single implants. Implant Dent 2005;14:94-103. 